\title{
Cholinesterase Activity in Health Workers Involved in Handling and Spraying of Organophosphorous Insecticides
}

\author{
Himanshu Madaan, Veena S Ghalaut, Ashuma Sachdeva, Rajesh Nair \\ Department of Biochemistry, Pt. B D Sharma Univ. of Health Sciences, Rohtak, Haryana-124001. \\ Indian Institute of Public Health-Gandhinagar Sardar Patel Institute Campus, Drive in Road, Thaltej, Ahmedabad-380054
}

\section{A B STR A C T}

\begin{abstract}
Background: Recent era of agricultural boon is partially the result of extensive use of insecticides and pesticides. But these compounds also have potential to significantly alter the ecosystem and can cause acute poisonings as well as long term detrimental health effects in humans. These compounds can cause toxicity through all routes of exposure. They exert their effect mainly by the inhibition of Acetylcholinesterase (AChE), which functions by removing acetylcholine (ACh) from its postsynaptic receptors. Aims and Objectives: Human exposure to Organophosphorous (OP) pesticides can develop lowered cholinesterase levels. The aim of the present study was to estimate the plasma levels of AChE in personnel involved in handling of these compounds, during the period of active spraying operations. Methodology: The present study was conducted on 38 subjects working as Multipurpose Health Workers (MPHW GROUP-1) and Field Workers (FW GROUP-2) involved in the actual spraying of the insecticides, in District Rohtak, Haryana, India to see the effect of exposure to OP insecticides. Plasma cholinesterase activity was measured by a kinetic method based on hydrolysis of butrylthiocholine. The data was statistically analyzed using SPSS statistical package (SPSS version 5.0). Results and interpretation: The mean cholinesterase activity in group-2 was lower by $27.76 \%$ than that in group- 1 and this difference was statistically significant $(p<0.05)$. The workers involved in actual spraying of the insecticides had a more marked reduction in the levels of Plasma AChE, compared to the workers involved only in the handling of the insecticides indicating that this group is at a bigger risk.
\end{abstract}

\section{INTRODUCTION}

An insecticide is a pesticide used against insects in all developmental forms. They may be natural or synthetic chemicals and may act either as ovicide, larvicide or a contact insecticide. The age of chemical insecticides began about 2000 years ago, with the use of natural products like pyrethrum and tobacco. Synthetic insecticides were introduced in 1940 with chemicals like Dichlorophenyl Trichloroethane (DDT). ${ }^{1}$ In the present times insecticides are widely used in agriculture, medicine, industry and household. In fact, the boon of agricultural productivity of the present time is partly due to the availability of potent and effective insecticides. But, nearly all insecticides have potential to significantly alter ecosystem; many are toxic to humans and others are concentrated in the food chain. In

Address for correspondence:

Phone No.: 09896091633

E-mail:rnair@iiphg.org

DOI: 10.5530/ijmedph.2.2011.5 humans, they are responsible for acute poisonings as well as for long term health effects, including cancer and adverse effects on reproduction. Therefore, it is very essential to balance needs with environment and health issues, when using insecticide and pesticide. The vast majority of insecticides targeted at insects, arthropods and nematodes are neurotoxic. They are capable of exerting a broad range of effects that ultimately results in mortality. At the whole organism level the insecticide effect may be either neuroexcitatory leading to hyperactivity, tremors and rigid paralysis or neuroinhibitory causing immobility and flaccid paralysis. $^{2}$

Organophosphates and Carbamates are, nowadays, widely used as insecticides and have been considered as potential chemical warfare agents. As an insecticide they are used widely for agriculture, vector control and domestic purpose. ${ }^{3}$ Household and agricultural products containing Organophosphorous (OP) pesticides are widely prevalent eg. insecticidal preparations and fertilizers for gardens, surface and room sprays, baits for cockroaches and other insects, shampoos against lice, pet preparations etc. In 
addition large scale internal and external control methods like fumigation and spraying, are also carried out especially in developing countries. These compounds can cause toxicity through all routes of exposure- dermal, oral, respiratory and even ocular. ${ }^{3}$

\section{Organophosphates poisoning: Health hazards}

OP pesticides are the most important cause of severe toxicity and death from acute poisoning worldwide, with more than 200,000 deaths each year in developing countries. ${ }^{4}$ OP insecticides inhibit the functions of a host of enzymes in the body (plasma and hepatic carboxylesterases, carboxylic acid hydrolases) but their main effect is the inhibition of Acetylcholinesterase (AChE), an enzyme that occurs in the CNS. It functions by removing acetylcholine (ACh) from its postsynaptic receptors. This results in hydrolysis of ACh into acetate and choline and ultimately, initiation of action potential at precise interval. Organophosphate insecticides bind to an acyl pocket (where ACh typically binds to AChE) and then a phosphate group of the OP binds to the serine amino acid at the active site on the AChE molecule thus preventing it from functioning. This binding is irreversible for all practical purposes with spontaneous regeneration taking days to weeks. In some cases, 'aging' of the AChE molecule may occur when part of OP is cleaved off and rest is left attached to AChE molecule making enzyme permanently inactive. The concentration of acetylcholine then builds up and hyperexcitation occurs. Signs of intoxication include restlessness, tremors, convulsions and paralysis. In contrast to OP insecticides the carbamate insecticides are fast and reversible acetylcholinesterase inhibitors. Both Organophosphorous and carbamate insecticides possess relatively high mammalian toxicity; however the carbamates are generally more hazardous because of the greater affinity they possess for the acetylcholinesterase enzyme. ${ }^{3}$

\section{Organophosphate poisoning: Sign and symptoms}

Organophosphates can be absorbed by all routes including inhalation, ingestion and dermal absorption. The toxicological effects of organophosphorus pesticides are almost entirely due to the inhibition of acetylcholinesterase in nervous system, resulting in respiratory, myocardial and neuromuscular transmission impairment. The main target organs are nervous system, respiratory tract and cardiovascular system. Signs and symptoms of acute organophosphate poisoning are an expression of effects caused by excess acetylcholine (cholinergic syndrome); and depend on area of cholinergic nervous system being affected. These areas may be-

- Muscarinic (postganglionic parasympathetic)

- Nicotinic (sympathetic and parasympathetic ganglionic and somatic neuromuscular junction)

- Central nervous system
The symptoms may occur in various combinations and can be manifest at different times. Systemic effects are, in general, similar, irrespective of route of absorption, but sequence and times may differ. Respiratory and ocular symptoms appear first after exposure to airborne organophosphates. Gastrointestinal symptoms and localized sweating are likely to appear after oral and dermal exposure, respectively.

\section{Organophosphate: Toxicity effects}

A few organophosphorus pesticides have produced socalled "Intermediate Syndrome" and delayed neuropathy, the latter apparently unrelated to acetylcholinesterase inhibition. This occurs either after initial improvement, approximately 1-8 days after acute poisoning. This results into muscle weakness leading to paralysis. Delayed neuropathy is initiated by an attack on a nervous tissue esterase distinct from cholinesterase. The target has esterase activity and is called neuropathy target esterase (NTE) (earlier known as neurotoxic esterase). Disorder develops not because of loss of esterase activity, but because of change in protein molecule that result from process of ageing of inhibited NTE. The catalytic activity of NTE appears in nervous tissue, even during the period of development of neuropathy. ${ }^{3}$

In addition to the above documented toxicity effects of OP insecticides, there are a few reported cases of prolonged paralysis from succinylcholine in patients poisoned with OP insecticides parathion and chlorpyrifos. ${ }^{5}$ Succinylcholine is the most important rapid acting depolarizing muscle relaxant during anesthesia. Its desirable short duration of action is controlled by plasma cholinesterase. In a study it was shown that toxicity of succinylcholine was potentiated several fold after OP pesticide administration in experimental mice and certain pesticides like chlorpyrifos had threshold values as low as $10 \mathrm{mg} / \mathrm{kg}$. Enhanced mortality from succinylcholine is generally observed when serum cholinesterase is inhibited by $55-94 \% .^{5}$

\section{METHODOLOGY}

The present study was conducted on 38 subjects working as Multipurpose Health Workers (MPHW) and Field Workers (FW) in a district of Haryana, India to see the effect of exposure to OP insecticides. The MPHW were involved only in maintaining the stock of insecticides whereas, all the FW (except one) were involved in actual spraying of the insecticides in rural as well as urban areas. They had no apparent signs and symptoms of insecticide toxicity. The study was carried out during the period of active spraying. Serum cholinesterase activity was measured by a kinetic method based on hydrolysis of butrylthiocholine. The kit was procured from Agappe Diagnostics, Ernakulum, India. 


\section{Principle $^{6}$}

Cholinesterase catalyses the hydrolysis of butrylthiocholine substrate forming butyrate and thiocholine.

Butrylthiocholine $+\mathrm{H}_{2} \mathrm{O}$ CHE Thiocholine + Butyrate

Thiocholine then reduces hexacyanoferrate to hexacyanoferrate. The decrease in the absorbance is followed at $405 \mathrm{~nm}$ and is proportional to the cholinesterase activity in the sample.

Normal range of cholinesterase activity is as follows:-

FEMALES: 3930-10800 U/L; MALES: 4620-11500 U/L

\section{RESULTS}

Out of the total 38 subjects 14 were MPHW'S (GROUP-1) and 24 were FW`S (GROUP-2) (Table-1).

All the FW'S were in the age group of 35-45 years except one who was 50 yrs old. The MPHW'S were in the age group of 30-42 years except two who were 48 years old. None of the workers were using any protective clothing or masks while handling the insecticide. The mean cholinesterase activity in group-2 (5410.56 \pm 957.66$)$ was lower by $27.76 \%$ than that in group-1 (7489.28 \pm 1106.95) (Table-2).

Abnormal cholinesterase activity was observed in 13.16\% $(05 / 38)$ of the total worker's. All the individuals with abnormal cholinesterase activity belonged to group-2 and none of the individuals in group- 1 had abnormal cholinesterase activity (Table-3).

\begin{tabular}{lcc}
\multicolumn{3}{l}{ Table 1: } \\
\hline Groups & Number & Involved in spraying/handling \\
\hline Group-1 & 14 & 14 \\
Group-2 & 24 & $23^{*}$ \\
Total & 38 & 37 \\
\hline
\end{tabular}

*One FW not involved in spraying due to intense dermal reaction.

\begin{tabular}{|c|c|c|}
\hline Groups & Range (u/l) & Mean \pm S.D \\
\hline Group-1 & $6066-9406$ & $7489.28 \pm 1106.95$ \\
\hline Group-2 & $3065-6687$ & $5410.56 \pm 957.66^{*}$ \\
\hline
\end{tabular}

In Group 2 the value of the $\mathrm{FW}$ not involved in spraying has been ignored. $* p<0.05$ for both the groups.

\begin{tabular}{lccc}
\multicolumn{4}{l}{ Table 3: Plasma AChE levels } \\
\multicolumn{1}{c}{ Observations } & Group-1 & Group-2 & Total \\
\hline $\begin{array}{l}\text { Workers showing } \\
\text { normal activity }\end{array}$ & 14 & 19 & 33 \\
$\begin{array}{l}\text { Workers showing } \\
\text { abnormal activity }\end{array}$ & 00 & $05(20.83 \%)$ & $05(13.16 \%)$ \\
Total & 14 & 23 & 37 \\
\hline
\end{tabular}

The above observations show that the plasma AChE levels were significantly decreased in workers who were involved in spraying operations. Although the pre-exposure or baseline levels of these workers were not available, but the reduction was quiet significant and ranged from $3.03-33.65 \%$ of the lower reference limit.

\section{DISCUSSION}

Unfortunately, some of the symptoms of organophosphorus toxicity can be confused with influenza, heat prostration, alcohol intoxication, exhaustion, hypoglycemia, asthma, gastroenteritis, pneumonia and brain hemorrhage. ${ }^{7}$ In the absence of a reliable history, diagnosis of organophosphorus pesticides poisoning is initially clinical. Foul smell (much like garlic) may be present in breath, feces or vomit or in contaminated clothing.

Cholinesterase levels are helpful in diagnosing organophosphorus pesticide poisoning, especially chronic, but not in managing the illness. Ideally, both plasma and red blood cell cholinesterase levels should be obtained in every case of suspected significant poisoning. Erythrocyte cholinesterase is a more accurate representation of nervous system $\mathrm{AChE}$, but it is more difficult to obtain. On the other hand, Plasma AChE (P AChE) levels may be a less accurate representation of nervous system. $\mathrm{AChE}$ are easier to assay and they decline faster. Although, PAChE assay is far from serving as a gold standard, but the erythrocyte $\mathrm{AChE}$ is also not error proof. Moreover, some compounds inhibit PAChE more effectively than they inhibit RBC AChE. It should be stressed that $\mathrm{P} A C h E$ activity does not always relate to the severity of poisoning but it can be used as a sensitive marker of exposure to OP or carbamate compounds. ${ }^{8}$

Many studies have stressed the importance of plasma cholinesterase levels for monitoring OP poisoning., ${ }^{9,10,11,12} \mathrm{It}$ has been proved that the effect of OP poisoning occurs early and is more marked in plasma cholinesterase than in red cell cholinesterase. A study by Orluwene et.al (2006) showed significant reduction in mean plasma cholinesterase activity in chronically exposed subjects $(4614 \pm 532)$ when compared with that of the control group (8095 \pm 575$).{ }^{9}$ There was no statistical difference in the mean red cell cholinesterase activity of the chronically exposed group $(7998$ $\pm 948)$ when compared with that of control $(8115 \pm 712)$. In another study by Mekonnen et al. (2005) it has been shown that mean values of plasma cholinesterase were generally lower in those exposed to insecticides but this reduction was statistically significant only in sprayers. ${ }^{10}$ Safi et. al (2005) have shown that mean activity of serum cholinesterase in sprayers $(3.28 \pm 0.12 \mathrm{kU} / \mathrm{L})$ was lower by $13.2 \%$ than that of the controls $(3.78 \pm 0.20 \mathrm{kU} / \mathrm{L}) .{ }^{11}$ A similar study by Catano et. al (2008) has shown that plasma cholinesterase 
levels from two exposed subgroup (pesticide applicator and other agricultural jobs) were significantly lower (1554 \pm 315 and $1532 \pm 340 \mathrm{U} / \mathrm{L})$ than those of controls $(1787 \pm$ $275 \mathrm{U} / \mathrm{L}){ }^{12}$ In the present study, workers involved in actual spraying of insecticides had a more marked reduction in the level of plasma cholinesterase, compared to workers involved only in handling of insecticides, indicating that this group is at a greater risk. So, the improved controls on workplace exposure to pesticides should be focused on these individuals.

Anyone exposed to OP pesticides will have lowered cholinesterase levels; therefore regular checking of their AChE levels should be done so that they can be alerted before decline can cause serious illness. Ideally, a pre exposure baseline AChE value should be established for any individual before they come in regular contact with organophosphates and carbamates. But excessive exposure to these pesticides can depress the AChE so markedly that a diagnosis can be made without previous baseline testing. If an individual's AChE levels drop 30\% below the original baseline level, immediate retesting should be done. Fortunately, the breakdown of AChE can be reversed and the levels will return to normal if pesticide exposure is stopped. ${ }^{6}$ Many developed nations are running AChE monitoring programs which serve as a useful and cost effective means of preventing organophosphate and carbamate overexposure. ${ }^{12}$

Chemical insecticides remain an important tool for managing insect pests of humans, animals and food and fiber crops. Although, compounds that are persistent in environment are no longer used, and the amounts sprayed have dropped from kilograms per acre to grams per acre of active ingredient, but still no insecticide is free from toxic effects on humans and environment. Repeated long term exposure to these insecticides may have their inherent complications. Therefore, it is recommended that workers who are exposed to OP pesticides on a regular basis should have a pre employment examination to determine their baseline cholinesterase levels and these tests should be repeated on a regular basis to determine whether exposure is occurring with sub clinical findings, especially during the season of active spraying. If RBC or P AChE falls significantly, workers should be taken off the job and should not return to work until their cholinesterase levels return to normal.

\section{CONCLUSION}

The inferences of results have been based on small sample size and may not be generalized. As the present study was not a randomly controlled double blind trial, it may have encountered number of biases such as selection bias, confirmatory bias, measurement bias and observer bias. It is recommended that based on the findings of present study further research may be conducted on a large sample size using more robust methodology. The results of present study reinforce the concept that exposure to insecticides do affect the AChE levels significantly and also signifies importance of pre exposure determination of baseline cholinesterase levels. Such pre exposure determination is carried out very strictly in developed countries but not in the developing countries like India. At workplace, universal precautions and improved controls should be adapted to prevent toxicities and possible health hazards among individuals due to their exposure to pesticides. Such workers should be covered through appropriate health insurance cover by their employer to secure their future from possible health hazards.

\section{REFERENCES}

1. Budavari, Susan, ed. (1996). The Merck Index, $12^{\text {th }}$ edition. Whitehouse Station, NJ: Merck \& Co.

2. Scharf ME. Neurological Effects of Insecticides. In Encyclopedia of Pest Management. Copyright (C 2003 by Marcel Dekker, Inc.

3. Organophosphorous Pesticides (PIM G001) HTML www.inchem.org/ documents/pims/chemical Thursday July02, 2009, 9.51 PM.

4. Eddelston M, Buckley NA, Eyer P, Dawson AH. Management of Acute Organophosphorous Pesticide Poisoning. Lancet, 2008; 371: 597-607.

5. Sparks SE, Quistad GB, Casida JE.Organophophorous pesticide-induced butrylcholinesterase inhibition and potentiation of succinylcholine toxicity in mice. J Biochem Mol Toxicol, 1999; 13:113-8.

6. Donald W Moss, Ralph A Henderson: Enzymes. In: Carl A Burtis, Edward $\mathrm{R}$ Ashwood eds. Teitz Textbook Of Clinical Chemistry second edition. Philadelphia: W B Saunders \& Company, 1999; 877-82.

7. Cholinesterase Inhibition. http://extoxnet.orst.edu/tibs/cholines.htm. Accessed on July 072009.

8. Chattonet $\mathrm{A}$, Lockridge o. Comparison of butrylcholinesterase and acetylcholinesterase [Review]. Biochem J, 1989; 260:625-34.

9. Orluwene CJ, Ejilemele AA. Comparison of red cell cholinesterase and plasma cholinesterase activities in early detection of organo-phosphorus toxicity in exposed industrial workers in Port Harcourt, Nigeria. Niger J Med, 2006; 15:314-7.

10. Mekonnen Y, Ejigu D. Plasma Cholinesterase levels of Ethiopian farm workers exposed to chemical pesticide. Occup Med (Lond), 2005; 55 : 504-5.

11. Safi JM, Abu Mourad TA, Yassin MM. Hematological biomarkers in farm workers exposed to organophosphorus pesticides in the Gaza Strip. Arch Environ Occup Health, 2005; 60:235-41.

12. Catano HC, Carranza E, Huamani C, Hernandez AF. Plasma Cholinesterase levels and health symptoms in Peruvian farm workers exposed to organophosphate pesticides. Arch Environ Contam Toxicol, 2008; 55:153-9.

13. Lessenger JE. Fifteen years of experience in cholinesterase monitoring of insecticide applicators. J Agromedicine, 2005; 10:49-56. 